\title{
Boron doping of silicon layers grown by liquid phase epitaxy
}

\author{
Michelle J. McCann*, Klaus J. Weber, Mladen Petravic, Andrew W. Blakers \\ Centre for Sustainable Energy Systems, Department of Engineering, Australian National University, Acton, 0200, Australia
}

Received 24 August 2001; accepted 20 February 2002

Communicated by J.B. Mullin

\begin{abstract}
This paper presents the results of a study of the incorporation of boron into silicon layers grown from a tin melt by liquid phase epitaxy. Boron was added to the melt through the use of boron-doped silicon source wafers. There is a large discrepancy between the amount of boron incorporated into the epitaxial layer and that available in the source wafer. This mismatch is explained by the gradual removal of boron from our system, most likely as a result of boron precipitation in the tin melt. This situation allows for control of the boron profile by adjusting the cooling rate and adding a dwell time. In this way, we have grown an epitaxial layer with an abrupt and highly doped p-type region at the epitaxial layer/substrate interface. This is useful for thin film solar cell applications as it allows the growth of a back surface field and a lightly doped bulk in a single growth step. (C) 2002 Elsevier Science B.V. All rights reserved.
\end{abstract}

Keywords: A3. Liquid phase epitaxy; B1. Boron; B1. Silicon; B3. Solar cells

\section{Introduction}

Thin film silicon solar cells are an attractive option for solar cell production because of their low cost potential resulting primarily from a reduced consumption of silicon compared with wafer based cells. Thin film layers have been grown or deposited on both foreign and native silicon substrates by a number of groups [1-3]. Chemical vapour deposition (CVD) and liquid phase epitaxy (LPE) are the most widely used techniques. The advantages of LPE include that it is a relatively low cost technique, it is capable of

\footnotetext{
*Corresponding author. Tel.: +61-2-6125-5941; fax: +61-26125-8873.

E-mail address: michelle.mccann@anu.edu.au (M.J. McCann).
}

producing high quality layers and it does not involve toxic gases. LPE grown layers generally have a low density of structural defects and a low recombination activity at grain boundaries [4]. LPE is being used for a number of thin film solar cell approaches, such as the solar cells by liquid phase epitaxy over porous silicon (SCLIPS) process developed by Canon [5] and the Epilift process developed at ANU [6].

Tin is one of the most useful solvents for silicon LPE due to a moderate silicon solubility at temperatures around $1000^{\circ} \mathrm{C}$, a low vapour pressure and toxicity, and the fact that it is electrically inactive in silicon. For solar cell fabrication, the relative abundance of tin compared with other suitable solvents such as indium is also an important advantage. One disadvantage of tin is that layers grown using a tin melt may 
have a reduced electronic quality since there are many misfit dislocations at the substrate/epitaxial layer interface [7].

A typical solar cell consists of three regions of different doping; a heavily doped p-type back surface field, a more lightly doped p-type bulk and an n-type emitter. The simplest cell design involves a p-type bulk onto which is formed both the back surface field and an emitter region using either separate growths or a diffusion. A more costeffective technique is to form the back surface field and bulk region within the same growth step. The ability to control the doping of the grown layers is very important because cell efficiency is a function of both the thickness and doping profile in each of the three regions.

Doping of the epitaxial layer may be achieved by the addition of dopant to the melt, either as a pure element, as a compound or by using a doped silicon source wafer. The doping profile is then determined by the amount of dopant in the melt, the segregation coefficient of the dopant as a function of temperature and the temperature profile used during growth. Commonly used dopants for silicon LPE include arsenic, antimony and phosphorous for the growth of n-type epitaxial layers, and gallium and aluminium for p-type epitaxial layers. Boron is another possible p-type dopant but has received comparatively little attention to date. The incorporation of boron into silicon epitaxial layers grown from a tin melt has been studied by Baliga. Baliga grew layers of 50 $100 \mu \mathrm{m}$ thickness between temperatures of $900^{\circ} \mathrm{C}$ and $1000^{\circ} \mathrm{C}$ using cooling rates of $0.2-7^{\circ} \mathrm{C} / \mathrm{min}$ and found that the amount of boron transferred to the epitaxial layer decreased exponentially with depth. Baliga inferred from the growths that boron is rapidly depleted from the melt and that all of the boron is incorporated into the epitaxial layer in a single growth $[8,9]$.

In this paper, we present results of our own detailed studies on the boron incorporation into silicon epitaxial layers grown from a tin melt.

\section{Experimental procedure}

Epitaxial layers were grown using LPE and the tipping boat method [10]. The melt was saturated at $970^{\circ} \mathrm{C}$ for $30 \mathrm{~min}$ and growth began at $970^{\circ} \mathrm{C}$. In most cases, the cooling rate was $2^{\circ} \mathrm{C} / \mathrm{min}$ and growth ended at $780^{\circ} \mathrm{C}$. The furnace was continually flushed with hydrogen, which was first passed through a palladium purifier. Source and substrate wafers were RCA cleaned and dipped in HF before loading into the LPE furnace. Substrate wafers were $40-90 \Omega \mathrm{cm}$ p-type (100), Cz. The tin was of six nines purity.

Doping profiles were measured using spreading resistance (SR) analysis and the total amount of boron present in very thin epitaxial layers was profiled using secondary ion mass spectrometry (SIMS). Boron 11 was profiled, but as boron is present in the normal isotopic ratio, the total amount of boron can be obtained by multiplying the SIMS results by 1.25 .

\section{Results and discussion}

\subsection{Doping profiles}

Fig. 1 shows doping profiles of two epitaxial layers grown from $970-780^{\circ} \mathrm{C}$ at a cooling rate of $2^{\circ} \mathrm{C} / \mathrm{min}$. A thickness of zero corresponds to the epitaxial layer/substrate interface, so that increasing depth corresponds to decreasing temperature

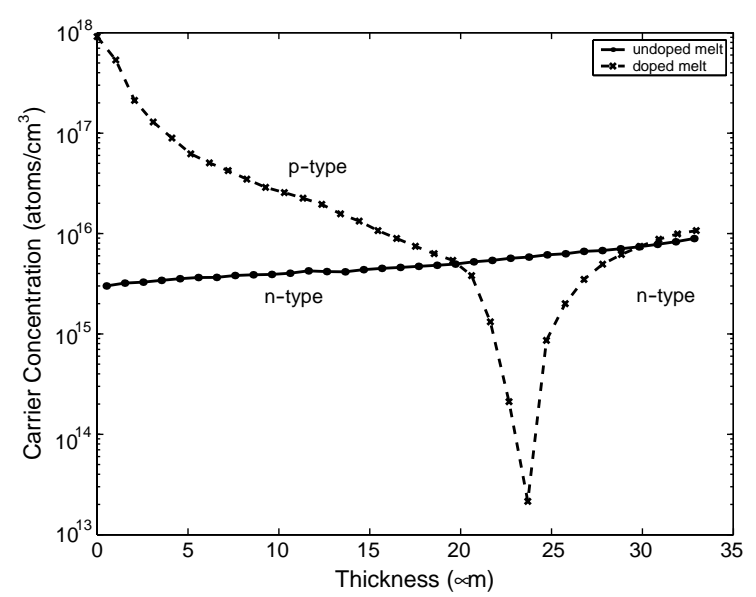

Fig. 1. An epitaxial layer grown using an undoped tin melt compared with an epitaxial layer grown using a heavily borondoped melt. The zero thickness point is the epitaxial layer/ substrate interface. 
and increasing time. The layers were grown using a tin melt saturated with two different silicon sources. The first source was undoped, and the second highly boron doped $(0.001-0.005 \Omega \mathrm{cm}$, which corresponds to a doping level of 2$11 \times 10^{19}$ atoms $/ \mathrm{cm}^{3}$ ). The undoped source results in a very low n-type doping, due to the presence of residual n-type impurities in the tin melt. Adding boron to the melt via the silicon source wafer results in p-type doping of the epitaxial layer. In the regions where the carrier concentration resulting from the doped silicon is more than an order of magnitude greater than the doping resulting from the plain source wafer, the carrier concentration can be assumed to approximate the amount of electrically active boron.

During growth, the amount of boron incorporated into the epitaxial layer drops rapidly and the surface is typically n-type. This is in qualitative agreement with the results of Baliga [8,9]. However, in contradiction to Baliga's assumption, we find that the amount of electrically active boron in the epitaxial layer is much less than the total amount of boron in the source wafer. Incorporation of all of the boron from the source wafer into the epitaxial layer in electrically active form should result in p-type epitaxial layer with a mean doping of at least $2 \times 10^{19}$ atoms $/ \mathrm{cm}^{3}$.

Fig. 2 shows the doping profile of an epitaxial layer grown immediately after the boron-doped epitaxial layer of Fig. 1. A lightly doped source

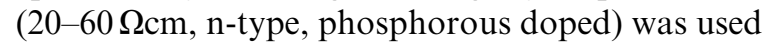
to saturate the melt for this second growth. While some residual boron was still present in the melt following the growth of the first epitaxial layer, the available concentration had dropped by more than an order of magnitude. With further growths, the boron concentration in the epitaxial layer continues to drop and approaches that of a layer grown from an undoped melt. The residual boron available for incorporation in the early stages of the second growth shown in Fig. 2 suggests that the segregation coefficient for boron from liquid tin into solid silicon decreases substantially between $970^{\circ} \mathrm{C}$ and $780^{\circ} \mathrm{C}$.

One possible explanation of the above results is that most of the boron incorporated into the epitaxial layers is electrically inactive. However,

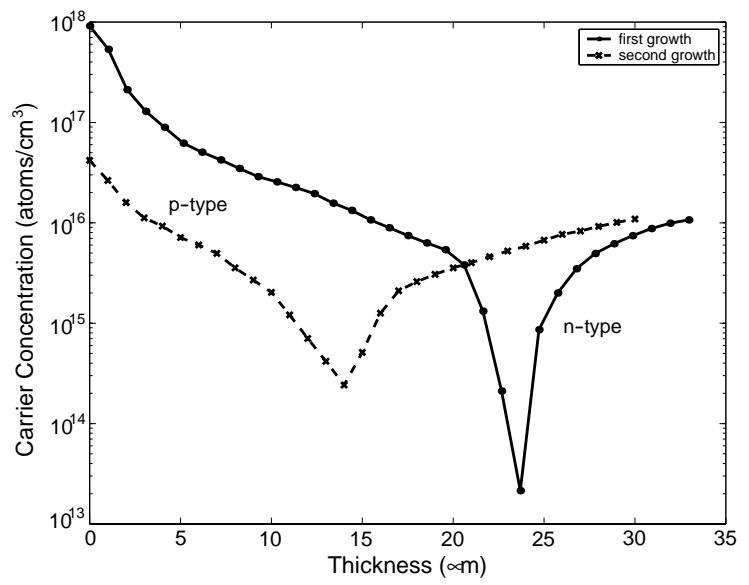

Fig. 2. A comparison of samples grown directly following each other without re-doping the melt. The first growth shows no further boron deposition at low temperatures (the epitaxial layer surface). However, at higher temperatures (close to the epitaxial layer/substrate interface of the second growth) a small amount of boron remains, and the first few microns are p-type.

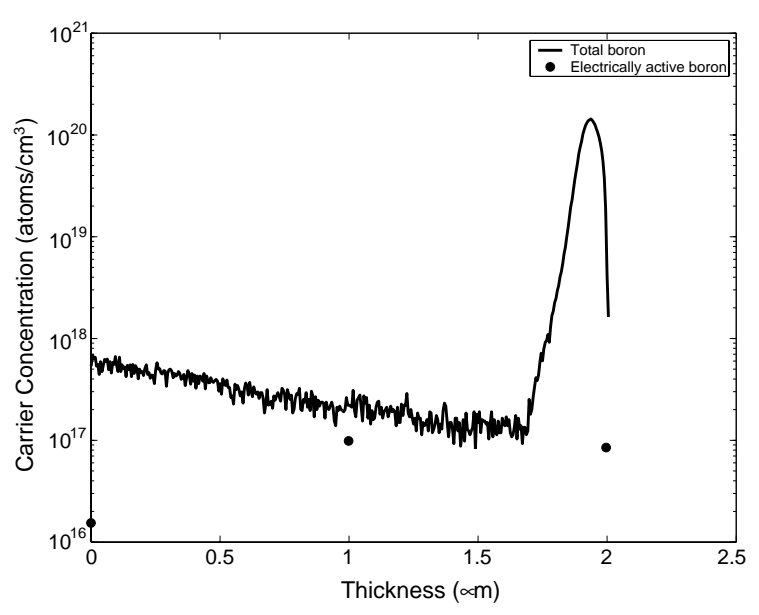

Fig. 3. A comparison of electrically active and total amounts of boron in a $2 \mu \mathrm{m}$ thick epitaxial layer. The surface peak in the 'total boron' curve is due to an ion-implantation step which was necessary for SIMS calibration.

SIMS measurements do not support this hypothesis. Fig. 3 shows a sample which has been profiled with both SIMS and SR analysis. The surface peak in the SIMS measurement is due to an ion implantation step done for calibration purposes. The surface levels (at $\sim 2 \mu \mathrm{m}$ thickness) of 
electrically active and total boron concentrations are in good agreement with each other. Different SIMS measurements on the same samples showed that doping levels were uniform over the epitaxial layer surface to within a factor of two.

We conclude that most of the boron present in the doped source wafers is not incorporated into the epitaxial layer and is not available for subsequent growths.

\subsection{Possible mechanisms of boron removal}

We considered three possible explanations for the apparent disappearance of boron from our system. Firstly, boron hydrides may form due to a reaction between boron in the melt and the hydrogen gas. Many $\mathrm{B}_{n} \mathrm{H}_{m}$ compounds including $\mathrm{B}_{2} \mathrm{H}_{6}$ and $\mathrm{B}_{4} \mathrm{H}_{10}$ have boiling points below $220^{\circ} \mathrm{C}$ and would therefore be gaseous at $970^{\circ} \mathrm{C}$. In order to test this hypothesis, it would be necessary to carry out growth in a hydrogen-free atmosphere. This is difficult since hydrogen is necessary to remove the thin native oxide layer which forms on the silicon surface and epitaxial growth will not occur on an oxide covered surface [7].

Secondly, boron may be incorporated into the graphite, with which the melt is in contact during growth and saturation. In order to test for this, epitaxial layers were grown in an arrangement which avoided all contact between the melt and the graphite during the process. Two growths were done, the first with a $30 \mathrm{~min}$ dwell time between saturation and growth and the second with a $4 \mathrm{~h}$ dwell time between saturation and growth. SIMS measurements show that, as with our earlier measurements, the long dwell time reduces the amount of boron available for incorporation into the epitaxial layer. This suggests that boron is not incorporated into the graphite crucible.

A further possibility is that boron precipitates may be formed within the tin melt. On investigation, this became the most likely explanation for the removal of available boron from our system. The solubility of boron in tin in our system is likely to be extremely low since no significant dissolution of boron into tin could be detected even at 1500 $1600^{\circ} \mathrm{C}$ in a hydrogen atmosphere [11]. In this case, it may be expected that agitation of the melt would result in an increase in the rate of precipitation of boron. This is supported by experiments in which the silicon substrate was placed on top of the melt during growth, rather than underneath it. In this arrangement, convection cells are set up within the melt during growth [12]. It was found that the boron concentration in the epitaxial layer decreased more rapidly in this case. We conclude that the most likely mechanism for the removal of available boron from our system is in the form of boron precipitates which remain in the tin melt.

\subsection{Application to solar cells}

In this section, we show how the results presented in this paper may be useful to thin film silicon solar cells. We have shown that the amount of boron present in the melt which may be incorporated into the growing epitaxial layer decreases with time. It is therefore possible to tailor the time-temperature profile of the growth to obtain specific doping profiles. A particular example is the formation of the back surface field and bulk of a thin film solar cell in a single growth step. Such a structure was obtained as follows. A tin melt was saturated from a heavily boron-doped source wafer at $970^{\circ} \mathrm{C}$ for $30 \mathrm{~min}$. Following saturation, the melt was tipped onto the substrate and cooled to $965^{\circ} \mathrm{C}$ at $2^{\circ} \mathrm{C} / \mathrm{min}$. This resulted in the growth of a thin layer, useful as a heavily doped back surface field. The temperature was then held constant at $965^{\circ} \mathrm{C}$ for $5 \mathrm{~h}$ in order to effect the removal of most of the available boron from our system. Finally, the melt was cooled to $780^{\circ} \mathrm{C}$ at $2^{\circ} \mathrm{C} / \mathrm{min}$ in order to produce the lightly doped bulk region. The resulting doping profile is shown in Fig. 4. Due to the presence of some residual boron in the melt following the $5 \mathrm{~h}$ dwell, the first half of the lightly doped bulk is p-type, while the remainder of the bulk is n-type due to the presence of donor impurities in the tin melt. A discontinuous profile as shown in Fig. 4 can usually only be obtained using LPE by doing two separate growths using differently doped melts and has correspondingly increased costs. The addition of other dopants, such as gallium, can be used to ensure that the base region of the 


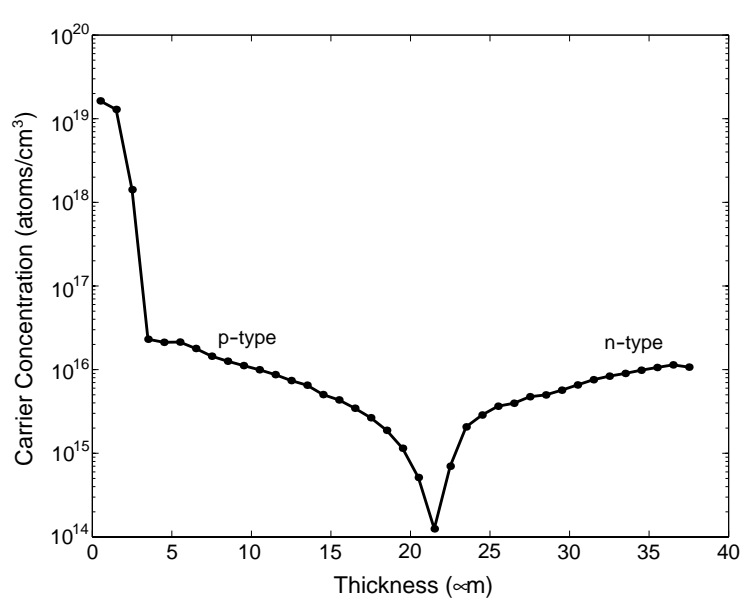

Fig. 4. $p$-type back surface field obtained on an epitaxial layer.

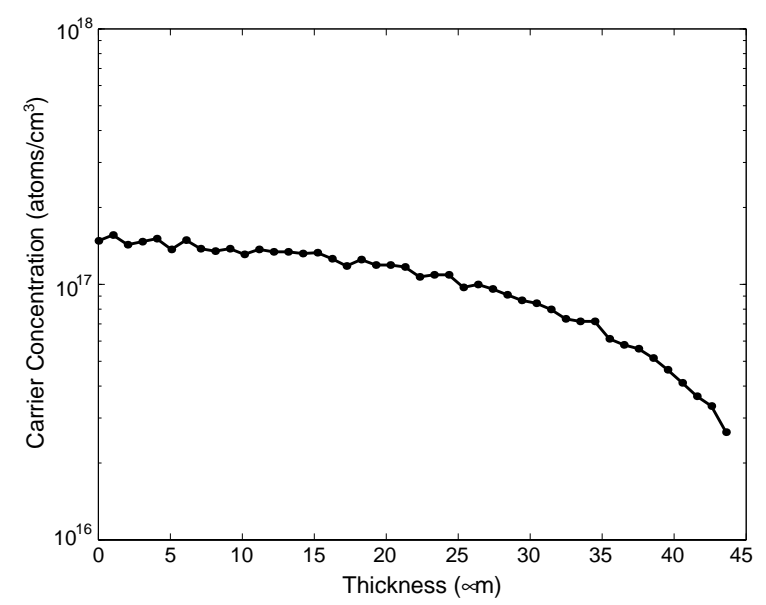

Fig. 5. Doping profile for an epitaxial layer grown using a gallium doped tin melt.

epitaxial layer is entirely p-type. Fig. 5 shows the doping profile for an epitaxial layer grown with the addition of gallium to a tin melt. Five hours is a long dwell time. Given that the available boron in the melt is significantly reduced during a typical growth of $2 \mathrm{~h}$, the $5 \mathrm{~h}$ period could be significantly reduced. Given also that the available boron is lost due to the formation of boron precipitates within the melt, stirring of the melt has been shown to further speed up this process. A long dwell time becomes less significant for larger batches.

\section{Conclusion}

The incorporation of boron into silicon grown using liquid phase epitaxy and a tin melt has been studied. Boron incorporation is a function of both time and temperature. The segregation coefficient for boron from liquid tin into solid silicon is temperature dependent and higher at higher temperatures. Boron incorporation decreases with time, probably due to the formation of boron precipitates which remain in the tin melt. Boron incorporated into the epitaxial layer is spatially uniform and electrically active. By choosing appropriate growing conditions, an abrupt and heavily doped p-type region may be formed at the substrate/epitaxial layer interface. This is useful as a back surface field for solar cell applications.

\section{Acknowledgements}

Financial support for this work by Origin Energy Ltd and the Australian Research Council is gratefully acknowledged. 'Epilift' is a registered trademark.

\section{References}

[1] J.H. Werner, R. Bergmann, R. Brendel, Festkörperprobleme/Adv. Solid State Phys. 34 (1994) 115.

[2] M.J. McCann, K.R. Catchpole, K.J. Weber, A.W. Blakers, Sol. Energy Mater. Sol. Cells 68 (2001) 135.

[3] K.R. Catchpole, M.J. McCann, K.J. Weber, A.W. Blakers, Sol. Energy Mater. Sol. Cells 68 (2001) 173.

[4] A. Voigt, B. Steiner, W. Dorsch, J. Krinke, M. Albrecht, H.P. Strunk, G. Wagner, J. Crystal Growth 166 (1996) 694.

[5] Shoji Nishida, Katsumi Bakagawa, Masaaki Iwane, Yukiko Iwasaki, Noritaka Ukiyo, Masaki Mizutani, Tatsumi Shoji, Si Film growth using liquid phase epitaxy method and its application to thin-film crystalline Si solar cell, in: Technical Digest of the International PVSEC-11, Sapporo, Hokkaido, Japan, 1999, p. 537.

[6] K.J. Weber, K. Catchpole, A.W. Blakers, J. Crystal Growth 186 (1998) 369.

[7] K. Weber, Liquid Phase epitaxy of silicon for thin film silicon solar cells, Ph.D. Thesis, Australian National University, 1997.

[8] B. Jayant Baliga, J. Electrochem. Soc. 133 (1986) 5C. 
[9] B. Jayant Baliga (Ed.), Epitaxial Silicon Technology Harcourt Brace Jovanovich, New York 1986, p. 177 (Chapter 3).

[10] B. Jayant Baliga, J. Electrochem. Soc. 129 (1982) 665.
[11] M. Hansen, K. Anderko, Constitution of Binary Alloys, McGraw-Hill book company inc., New York, 1958, p. 245.

[12] Masakazu Kimura, Akira Tanaka, Tokuzo Sukegawa, J. Crystal Growth 109 (1991) 181. 